\title{
Invasive Lobular Breast Carcinoma, Signet Ring Variant
}

National Cancer Institute

\section{Source}

National Cancer Institute. Invasive Lobular Breast Carcinoma, Signet Ring Variant. NCI

Thesaurus. Code C54691.

An invasive lobular carcinoma characterized by the presence of malignant epithelial cells with large intracytoplasmic lumina that cause displacement of the nuclei towards one pole of the cells. 